\title{
Dental and Dental Hygiene Students' Perceptions of Status Quo, Benefits of, and Curricular Suggestions for Shared Learning: On the Road to IPE?
}

\begin{abstract}
Martha J. McComas, Julianne Doctor, Marita R. Inglehart
Abstract: In 29 U.S. academic institutions, dental and dental hygiene students are educated on the same campus. The aims of this study were to explore the perceptions of dental and dental hygiene students on the same campus concerning the status quo of shared educational experiences, the benefits of shared education, and their curricular suggestions for shared education. Additionally, the study investigated whether the number of shared courses was correlated with the perceived benefits of shared learning. A survey was sent in 2016 to a chief administrator at all 29 dental school and dental hygiene programs that were on the same campus, with a request that the administrators forward the invitation email to all their students. A total of 375 dental and 117 dental hygiene students at 12 universities responded. The students reported that three of the nine dental hygiene programs and two of the six dental programs had no shared courses. The majority of dental/dental hygiene students agreed or agreed strongly that having joint classes would allow them to develop better relationships between dental and dental hygiene students $(57 \% / 57 \%)$ and gain a better understanding of each other's roles $(50 \% / 63 \%)$ and of what the other discipline "is all about" $(54 \% / 46 \%)$. Compared to dental hygiene students, dental students were less supportive of suggestions for curricular interventions such as partnering up in lab (on a five-point scale with $5=$ most positive: 3.99 vs. $3.56 ; \mathrm{p}<0.001$ ), using in-class time for shared group projects ( 3.83 vs. $3.27 ; \mathrm{p}<0.001$ ), and shadowing in clinics ( 4.26 vs. $3.16 ; \mathrm{p}<0.001)$. The more courses dental and dental hygiene students jointly attended, the higher their percentage of clinic time spent on collaborative care $(r=0.19 ; \mathrm{p}<0.001)$. Having dental and dental hygiene programs on the same campus offers opportunities for shared learning, and this study's results suggest those opportunities may translate into increased shared learning.
\end{abstract}

Martha J. McComas, RDH, MS, is Clinical Assistant Professor, Department of Periodontics and Oral Medicine, Division of Dental Hygiene, University of Michigan School of Dentistry; Julianne Doctor, BS, is Research Assistant, Department of Periodontics and Oral Medicine, University of Michigan School of Dentistry; and Marita R. Inglehart, Dr phil habil, is Professor, Department of Periodontics and Oral Medicine, School of Dentistry and Adjunct Professor, Department of Psychology, College of Literature, Science, and Arts, University of Michigan. Direct correspondence to Dr. Marita R. Inglehart, Department of Periodontics and Oral Medicine, School of Dentistry, University of Michigan, Ann Arbor, MI 48109-1078; 734-763-8073; mri@umich.edu.

Keywords: dental education, dental hygiene education, dental students, dental hygiene students, intraprofessional education, collaborative learning, educational methodology, professional roles

Submitted for publication 6/4/18; accepted 9/12/18; first published online 1/28/19

doi: 10.21815/JDE.019.028

$\mathrm{T}$ The importance of interprofessional education (IPE) and care (IPC) was first discussed in dentistry when the Institute of Medicine (IOM) report entitled Dental Education at the Crossroads: Challenges and Change was published in 1995. ${ }^{1}$ This report described dental education and dentistry as "vulnerable" because they were isolated from other health professions and in need of an integration with other professions in research, education, and patient care. An early call for IPE and IPC was also part of the 2000 IOM report To Err Is Human:
Building a Safer Health System, which argued that comprehensive patient care would be compromised if a team approach were not taken. ${ }^{2}$ The five core competencies presented in the 2003 IOM report Health Professions Education: A Bridge to Quality that described how health care should function also included the core competency that patient-centered care should be provided in interdisciplinary teams. ${ }^{3}$ Globally, the call for IPE and IPC received worldwide attention when the World Health Organization (WHO) published its "Framework for Action 
on Interprofessional Education and Collaborative Practice" in $2010 .{ }^{4}$ This publication defined IPE as occurring when students from two or more health professions learn about, from, and with each other and defined IPC as care provided by health care providers working together to provide better health care for patients.

Empirical investigations have sought to define the status quo of IPE in U.S. dental schools and dental hygiene programs. These efforts began with a study published in 2006 by Rafter et al. who found only scarce intentional IPE efforts at that time, ${ }^{5}$ despite increased attention to collaborative care encouraged by the surgeon general's report on oral health in $2000 .^{6}$ Wilder et al. published a study in 2008 that argued dental professionals needed to be incorporated into cross-disciplinary treatment collaborations for the improvement of the oral health of the U.S. population. ${ }^{7}$ Formicola's study group to explore IPE activities in U.S. and Canadian dental schools published its report in $2012 .{ }^{8}$ Furgeson et al. then used a slightly revised form of the Formicola survey to assess IPE content in U.S. dental hygiene programs. ${ }^{9}$ The Commission on Dental Accreditation (CODA) revised its predoctoral dental accreditation standards to include IPE in 2013 (Standards 1-9 and 2-19), ${ }^{10}$ and, in 2016, revision of the CODA standards for dental hygiene programs followed (Standard 2-19). ${ }^{11}$

Many of the benefits of IPE, as well as distinctive ones, are found in intraprofessional education, defined by the American Dental Education Association (ADEA) as "when students in two or more oral health professions learn, and provide patient care together, in a fashion that promotes lifelong collaboration." ${ }^{\prime 2}$ Excellent opportunities for shared learning and collaborative care exist on the 29 campuses in the U.S. that we identified as having both dental schools and dental hygiene programs. In 2012, Formicola et al. identified 31 dental schools that had a dental hygiene program on their campus and five schools that collaborated with off-campus dental hygiene programs. ${ }^{8}$ In 2015, Furgeson et al. reported that, of the 102 responding dental hygiene programs, 20 had a dental school on their campus, and $28 \%$ collaborated with a dental school on a different campus. ${ }^{9}$ While those studies focused on administrators' perspectives, no research has so far explored how dental and dental hygiene students in programs on joint campuses perceive their shared educational experiences.

Previous research concerning intraprofessional experiences of dental and dental hygiene students showed that volunteer activities, lecture courses in basic or behavioral sciences, clinical activities/shared clinical duties, and community service/servicelearning experiences were most widely used. . $^{8,9,12,13}$ Classroom or lecture-based activities included joint classes concerning the roles and responsibilities of other disciplines and professions, team skill-building, community and preventive health, and ethics. ${ }^{13}$ However, specific analyses of the status quo of shared dental and dental hygiene learning on campuses with both a dental school and a dental hygiene program are missing thus far. The first objective of our study was thus to investigate dental and dental hygiene students' perceptions of those shared educational experiences.

It is also worthwhile to consider the benefits these students perceive in shared educational experiences. In Brame et al.'s study, when dental and dental hygiene students' perceptions of intraprofessional education were assessed, the students mentioned the benefit of improved communication and perceived that these improvements would benefit their patients. ${ }^{14}$ In Jones et al.'s study, dental and dental hygiene students reported having high expectations for the benefits of intraprofessional education and valued the team-based approach to patient care. ${ }^{15}$ However, dental and dental hygiene students' perceived benefits of shared learning on a common campus had not previously been researched, so our second objective was to do that. In addition, no research so far had asked students for suggestions of joint educational activities for dental and dental hygiene students. Student feedback might increase educators' repertoire of educational approaches, as in Brame et al.'s study in which students recommended more clinical integration. ${ }^{14}$ Our third objective thus was to ask dental and dental hygiene students on the same campuses for their curricular suggestions for joint learning. Our final objective was to explore whether the number of joint courses for dental and dental hygiene students on the same campuses and the length of those programs were positively correlated with increased perceptions of benefits of shared education.

The aims of this study were to explore the perceptions of dental and dental hygiene students on the same campus concerning the status quo of shared educational experiences, the benefits of shared education, and their curricular suggestions for shared education. Additionally, the study investigated whether the number of shared courses was correlated with the perceived benefits of shared learning. 


\section{Methods}

This study was determined to be exempt from Institutional Review Board (IRB) oversight by the Health Sciences and Behavioral Sciences IRB at the University of Michigan in June 2016 (\#HUM00111524). An a priori power analysis with the program package $G^{*}$ Power 3.1.2 (www.psycho. uni-duesseldorf.de/abteilungen/aap/ gpower3) was conducted to determine the sample size needed to have the power to test hypotheses concerning differences in the average responses of dental vs. dental hygiene students. It was assumed that twosided hypotheses would be tested, using a t-test for independent samples, with alpha $=0.05$, power $=0.90$, medium effect size of 0.50 on a five-point scale, and assuming the allocation ratio of dental hygiene to dental students would be 1:3. The results showed that a sample size of 86 dental hygiene students and 258 dental students would be required to have the power to test these hypotheses.

Data were collected with a web-based anonymous survey sent to students at all 29 dental school and dental hygiene programs on the same campuses. We determined those programs and collected contact information for their administrators from the institutions' websites in summer 2016. A recruitment email was sent to all directors of those dental hygiene programs and all academic deans of those dental schools. The email informed them about the study and asked them to forward an attached recruitment email to their students. This recruitment email explained the purpose of the study and provided a web-link to an anonymous survey. No follow-up emails were sent.

The survey questions were created by the authors based on dental and dental hygiene students' responses to an open-ended question included as a last question on a final exam in a joint dental-dental hygiene behavioral science class at the University of Michigan in December 2015. This question asked students to comment on the status of intraprofessional efforts with dental and dental hygiene students and to suggest ideas for curricular change. The students received an extra point for providing an answer to this question, so all 32 dental hygiene and 109 dental students in the joint class responded. We content analyzed the responses, and the results were the basis for drafting the survey used in this study. This draft survey was pilot tested with nine dental and dental hygiene students. Their comments were used to finalize the survey.
The final survey was an anonymous online survey of four parts. Part 1 asked about students' characteristics such as age, gender, year in program, and prior college degrees. Part 2 asked about shared classes and clinical activities they had participated in during their dental or dental hygiene education. Part 3 consisted of questions on benefits of shared activities and the knowledge they had of their own and the other oral health discipline's roles. Part 4 asked for curricular suggestions concerning classroom-based, preclinical, and clinical joint activities. One openended question at the end of the survey asked students to provide their thoughts concerning shared learning with dental and dental hygiene students.

The data were exported from the website as an SPSS data file, Version 24.0 (IBM Corp., Armonk, NY, USA). Descriptive statistics such as percentages, frequencies, and means were computed to provide an overview of the students' responses. Inferential statistics, specifically independent sample t-tests, were used to determine whether the average responses of the dental vs. dental hygiene students were significantly different. Pearson correlation coefficients were computed to assess relationships between the constructs of interest. A Bonferroni type adjustment was used to protect the data from Type I error due to the many statistical tests being performed simultaneously. The significance level was therefore lowered to $\mathrm{p}<0.001$ to help avoid false-positive results.

\section{Results}

Data were collected from 117 dental hygiene students in nine U.S. dental hygiene programs and from 375 dental students in six U.S. dental schools. According to the a priori power analysis, the number of responses was sufficient to test the hypotheses of interest. All respondents came from institutions that had a dental school and dental hygiene program on the same campus.

While $95 \%$ of the participating dental hygiene students were female, only $45 \%$ of the participating dental students were female (Table 1). The dental hygiene students ranged from 19 to 47 years of age and the dental students from 21 to 44 years of age. No dental hygiene program was four years long, but some had required a previous year of education in prerequisites. The dental hygiene students thus reported that they were in the second year (61\%), third year $(20 \%)$, or fourth year $(19 \%)$ of their program. 
Table 1. Characteristics of participating schools/programs and students

\begin{tabular}{|c|c|c|}
\hline Characteristic & $\begin{array}{c}\text { Dental Hygiene } \\
\mathrm{N}=117\end{array}$ & $\begin{array}{l}\text { Dental } \\
N=375\end{array}$ \\
\hline \multicolumn{3}{|l|}{ Data submission by school/program } \\
\hline Data were submitted only by dental students & 0 & 2 \\
\hline Data were submitted only by dental hygiene students & 5 & 0 \\
\hline Data were submitted by dental and dental hygiene students & 4 & 4 \\
\hline \multicolumn{3}{|l|}{ Students' gender } \\
\hline Male & $6(5 \%)$ & $199(53 \%)$ \\
\hline Female & $111(95 \%)$ & $176(47 \%)$ \\
\hline \multicolumn{3}{|l|}{ Students' age in years } \\
\hline Mean (SD) & $24.2(5.145)$ & $25.1(3.029)$ \\
\hline Range & $19-47$ & $21-44$ \\
\hline \multicolumn{3}{|l|}{ Students' year in program } \\
\hline 1 & - & $118(32 \%)$ \\
\hline 2 & $70(61 \%)$ & $163(44 \%)$ \\
\hline 3 & $23(20 \%)$ & $75(20 \%)$ \\
\hline 4 & $22(19 \%)$ & $17(5 \%)$ \\
\hline \multicolumn{3}{|l|}{ Students' type } \\
\hline In-state & 107 (92\%) & $258(69 \%)$ \\
\hline Out-of-state & $9(8 \%)$ & $102(27 \%)$ \\
\hline International & 0 & $13(4 \%)$ \\
\hline
\end{tabular}

The participating dental students were mostly in the first year (32\%) or second year (44\%), with only $20 \%$ being third-year and 5\% fourth-year students. Most responding dental and dental hygiene students were in-state students $(69 \% / 92 \%)$.
The first objective was to assess the students' perceptions of the status quo of joint educational experiences. Students in six of the nine dental hygiene programs and four of the six dental schools reported having had joint didactic courses (Table 2). Students

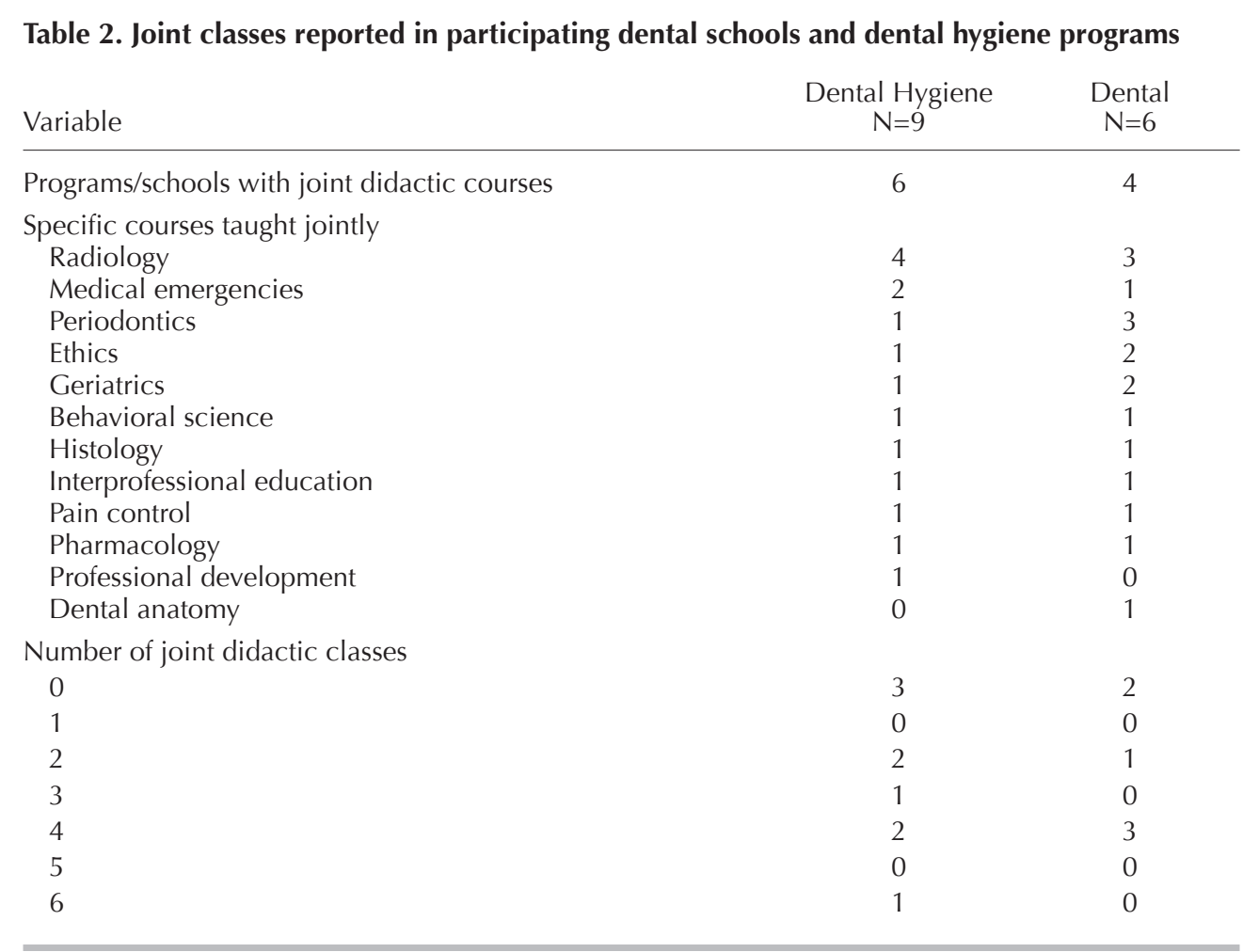


in four dental hygiene and three dental programs reported that they had joint radiology courses, and one dental and two dental hygiene programs reported having joint medical emergency courses. Students in three dental schools reported having radiology and periodontics courses held jointly with dental hygiene students. Students in two dental schools reported having joint ethics and geriatrics courses. Respondents reported that other courses such as behavioral science, histology, pain control, and pharmacology were being held jointly as well. While students in three dental hygiene and two dental programs reported no joint classes, students in one dental hygiene program reported that they had six joint classes with dental students, and students in three dental schools reported having four classes with dental hygiene students. Overall, these results showed the wide range of practices related to shared classroom-based and clinical experiences.

The second objective was to assess the students' perceived benefits of their joint educational experiences. The students answered ten questions about potential benefits of these shared efforts. We factor analyzed the responses to identify underlying factors. Four of the ten items loaded on a first factor that we described as the "benefits of joint classes" index. On average, students agreed or were neutral in their responses to the question if having joint classes allowed them to learn about what the profession of dentistry or dental hygiene was about (on a five-point scale with $1=$ disagree strongly: dental 3.25 versus dental hygiene 3.47) (Table 3). The mean responses to all questions were neutral to slightly positive, and

Table 3. Participants' responses concerning benefits of shared education and curricular suggestions by type of student

\begin{tabular}{|c|c|c|c|c|c|c|c|c|}
\hline Item & Students & 1 & 2 & 3 & 4 & 5 & Mean & p-value \\
\hline \multicolumn{9}{|l|}{$\begin{array}{l}\text { Joint classes with dental/dental } \\
\text { hygiene students allow me to: }\end{array}$} \\
\hline \multirow{2}{*}{$\begin{array}{l}\text { Learn what dentistry/dental } \\
\text { hygiene is all about. }\end{array}$} & $\mathrm{DH}$ & $10 \%$ & $13 \%$ & $23 \%$ & $33 \%$ & $13 \%$ & 3.47 & 0.086 \\
\hline & $\mathrm{D}$ & $7 \%$ & $19 \%$ & $27 \%$ & $30 \%$ & $24 \%$ & 3.25 & \\
\hline \multirow{2}{*}{$\begin{array}{l}\text { Gain better understanding of } \\
\text { the roles of dentists/dental } \\
\text { hygienists. }\end{array}$} & $\mathrm{DH}$ & $10 \%$ & $8 \%$ & $20 \%$ & $36 \%$ & $27 \%$ & 3.63 & 0.013 \\
\hline & $\mathrm{D}$ & $6 \%$ & $19 \%$ & $25 \%$ & $36 \%$ & $14 \%$ & 3.32 & \\
\hline \multirow{2}{*}{$\begin{array}{l}\text { Get to know dental/dental } \\
\text { hygiene students better. }\end{array}$} & $\mathrm{DH}$ & $13 \%$ & $12 \%$ & $25 \%$ & $22 \%$ & $28 \%$ & 3.40 & 0.726 \\
\hline & $\mathrm{D}$ & $5 \%$ & $15 \%$ & $25 \%$ & $41 \%$ & $14 \%$ & 3.44 & \\
\hline \multirow{2}{*}{$\begin{array}{l}\text { Develop better interprofessional } \\
\text { relationships. }\end{array}$} & $\mathrm{DH}$ & $9 \%$ & $10 \%$ & $24 \%$ & $43 \%$ & $14 \%$ & 3.44 & 0.464 \\
\hline & $\mathrm{D}$ & $4 \%$ & $13 \%$ & $27 \%$ & $27 \%$ & $30 \%$ & 3.52 & \\
\hline \multirow{2}{*}{$\begin{array}{l}\text { Benefits of joint classes index } \\
(\text { Cronbach's alpha }=0.915)\end{array}$} & $\mathrm{DH}$ & \multicolumn{2}{|c|}{ Mean 3.52} & \multicolumn{2}{|c|}{ SD 1.134} & \multicolumn{2}{|c|}{ Range 1-5 } & 0.356 \\
\hline & $\mathrm{D}$ & \multicolumn{2}{|c|}{ Mean 3.41} & \multicolumn{2}{|c|}{ SD 0.960} & \multicolumn{2}{|c|}{ Range 1-5 } & \\
\hline \multicolumn{9}{|l|}{ Students' suggestions } \\
\hline \multirow{2}{*}{$\begin{array}{l}\text { Discussions of professional roles } \\
\text { should occur in joint classes. }\end{array}$} & $\mathrm{DH}$ & $4 \%$ & $10 \%$ & $11 \%$ & $43 \%$ & $41 \%$ & 4.16 & $<0.001$ \\
\hline & $\mathrm{D}$ & $4 \%$ & $7 \%$ & $21 \%$ & $51 \%$ & $17 \%$ & 3.72 & \\
\hline \multirow{2}{*}{$\begin{array}{l}\text { Activities concerning } \\
\text { professional roles should be } \\
\text { integrated into joint classes. }\end{array}$} & $\mathrm{DH}$ & $3 \%$ & $10 \%$ & $14 \%$ & $41 \%$ & $41 \%$ & 4.18 & $<0.001$ \\
\hline & $\mathrm{D}$ & $3 \%$ & $7 \%$ & $26 \%$ & $49 \%$ & $15 \%$ & 3.65 & \\
\hline \multirow{2}{*}{$\begin{array}{l}\text { A lecture about professional } \\
\text { roles should be presented in } \\
\text { joint classes. }\end{array}$} & $\mathrm{DH}$ & $2 \%$ & 0 & $11 \%$ & $38 \%$ & $49 \%$ & 4.32 & $<0.001$ \\
\hline & $\mathrm{D}$ & $4 \%$ & $5 \%$ & $22 \%$ & $52 \%$ & $18 \%$ & 3.47 & \\
\hline \multirow{2}{*}{$\begin{array}{l}\text { IPE helps dental and dental } \\
\text { hygiene students understand } \\
\text { each other's roles better. }\end{array}$} & $\mathrm{DH}$ & $3 \%$ & $3 \%$ & $12 \%$ & $42 \%$ & $43 \%$ & 3.73 & $<0.001$ \\
\hline & $\mathrm{D}$ & $3 \%$ & $8 \%$ & $19 \%$ & $53 \%$ & $17 \%$ & 4.23 & \\
\hline \multirow{2}{*}{$\begin{array}{l}\text { Dental hygienists play an } \\
\text { important role in a dental team. }\end{array}$} & $\mathrm{DH}$ & $2 \%$ & 0 & $4 \%$ & $8 \%$ & $86 \%$ & 4.76 & $<0.001$ \\
\hline & $\mathrm{D}$ & $10 \%$ & $10 \%$ & $7 \%$ & $38 \%$ & $54 \%$ & 4.43 & \\
\hline \multirow{2}{*}{$\begin{array}{l}\text { IPE helps dental and hygiene } \\
\text { students develop better } \\
\text { professional relationships. }\end{array}$} & $\mathrm{DH}$ & $3 \%$ & $3 \%$ & $10 \%$ & $50 \%$ & $35 \%$ & 4.12 & $<0.001$ \\
\hline & $\mathrm{D}$ & $3 \%$ & $7 \%$ & $22 \%$ & $53 \%$ & $16 \%$ & 3.73 & \\
\hline \multirow{2}{*}{$\begin{array}{l}\text { Professional role index } \\
\text { (Cronbach's alpha=0.889) }\end{array}$} & $\mathrm{DH}$ & \multirow{2}{*}{\multicolumn{2}{|c|}{$\begin{array}{l}\text { Mean } 4.30 \\
\text { Mean } 3.83\end{array}$}} & \multirow{2}{*}{\multicolumn{2}{|c|}{$\begin{array}{l}\text { SD } 0.689 \\
\text { SD } 0.716\end{array}$}} & \multirow{2}{*}{\multicolumn{2}{|c|}{$\begin{array}{l}\text { Range } 1-5 \\
\text { Range } 1.17-5\end{array}$}} & $<0.001$ \\
\hline & $\mathrm{D}$ & & & & & & & \\
\hline
\end{tabular}

$\mathrm{DH}=$ dental hygiene students, $\mathrm{D}=$ dental students

Note: Response options were $1=$ disagree strongly, $2=$ disagree, $3=$ neutral, $4=$ agree, and $5=$ agree strongly. The survey items used the terms "interprofessional," "interprofessional education," and "IPE" to refer to shared learning or practice between dentistry and dental hygiene. 
the dental versus dental hygiene students' responses did not differ significantly.

Six items loaded on a second factor that we described as the "professional role" index. For each of these six statements, the dental hygiene students had significantly more positive average responses than did the dental students. Overall, the students differed significantly in their responses concerning their agreement with statements such as "Discussions of professional roles should occur in joint classes" and "Dental hygienists play an important role on the dental team."

The third objective explored the respondents' curricular suggestions concerning shared education for dental and dental hygiene students. A set of 19 items focused on curricular suggestions for classroom-based, preclinical/lab-based, and clinical learning (Table 4). A factor analysis showed that responses to the 19 statements loaded on three factors. On the first factor, a "classroom and preclinical settings" index, 12 of the 19 items loaded. Comparison of the mean responses to the single items showed that the dental hygiene students agreed more strongly than did the dental students with all but one of these items. Five of the 19 items loaded on a second factor: a "clinical setting" index. Again, the dental hygiene students' responses were on average significantly more positive than the dental students' responses.

In addition to the closed-ended questions, a final open-ended question asked for general feedback concerning students' shared learning experiences. A total of 137 dental students and 41 dental hygiene students provided positive feedback about shared learning, stressing that its benefits were clearly perceived (Table 5). Most of these responses were concerned with clinic- and classroom-based activities. While 22 dental students reported that shared dental-dental hygiene education in the clinical setting was beneficial, 11 stated that it should be enforced in the clinic. Curricular suggestions were also made in the open-ended remarks. For example, 21 dental students and six dental hygiene students reported they would like to have more shared interactions in classroom settings. Also, 15 dental students and four

Table 4. Participating dental and dental hygiene students' agreement with curricular suggestions for shared classroom, preclinical, and clinical education

\begin{tabular}{|c|c|c|c|}
\hline Suggestion & Dental & $\begin{array}{l}\text { Dental } \\
\text { Hygiene }\end{array}$ & p-value \\
\hline \multicolumn{4}{|l|}{ Classroom and preclinical settings } \\
\hline Assigned seating would help students to interact more with each other. & 3.05 & 3.05 & 0.976 \\
\hline Dental and dental hygiene students should be partnered up for class work. & 3.23 & 3.57 & 0.004 \\
\hline Class time should be set aside for allowing students to communicate with each other. & 3.31 & 3.85 & $<0.001$ \\
\hline $\begin{array}{l}\text { More in-class time should be allotted for students to work on interdisciplinary } \\
\text { group projects. }\end{array}$ & 3.27 & 3.83 & $<0.001$ \\
\hline More in-class group assignments would help facilitate interprofessional cooperation. & 3.12 & 3.57 & $<0.001$ \\
\hline Partnering up in lab would help me to get to know students better. & 3.56 & 3.99 & $<0.001$ \\
\hline I would like to work more collaboratively in labs. & 3.16 & 3.97 & $<0.001$ \\
\hline $\begin{array}{l}\text { Interdisciplinary group projects would help facilitate more interactions between } \\
\text { students in classes and labs. }\end{array}$ & 3.39 & 3.75 & 0.001 \\
\hline Students should be assigned to group projects throughout the term. & 2.88 & 3.33 & 0.001 \\
\hline $\begin{array}{l}\text { Unique roles in a group project should be assigned to group members according to } \\
\text { their program. }\end{array}$ & 3.18 & 3.54 & 0.004 \\
\hline I would like to take more interprofessional courses with students. & 3.20 & 3.89 & $<0.001$ \\
\hline Students should share more educational experiences with one another. & 3.48 & 4.12 & $<0.001$ \\
\hline Classroom and preclinical settings index (Cronbach's alpha=0.911) & 3.24 & 3.74 & $<0.001$ \\
\hline \multicolumn{4}{|l|}{ Clinical setting } \\
\hline Dental and dental hygiene students should shadow one another in the clinics. & 3.16 & 4.26 & $<0.001$ \\
\hline Students should practice patient "hand-off" in a clinical setting. & 3.68 & 4.16 & $<0.001$ \\
\hline Dental and dental hygiene students should work together in clinic. & 3.89 & 4.39 & $<0.001$ \\
\hline Dental and dental hygiene students should cooperate more in clinical settings. & 3.90 & 4.38 & $<0.001$ \\
\hline I believe that dentists are partners in the clinics. & 3.98 & 4.25 & 0.013 \\
\hline IPE helps students develop good communication skills when working together. & 3.69 & 4.27 & $<0.001$ \\
\hline I would like to work more collaboratively in clinics. & 3.85 & 4.29 & $<0.001$ \\
\hline Clinical setting index (Cronbach's alpha $=0.875)$ & 3.64 & 4.26 & $<0.001$ \\
\hline
\end{tabular}

Note: Response options were $1=$ disagree strongly, $2=$ disagree, $3=$ neutral, $4=$ agree, and $5=$ agree strongly. The survey items used the terms "interprofessional," "interprofessional education," and "IPE" to refer to shared learning or practice between dentistry and dental hygiene. 
Table 5. Open-ended responses concerning dental and dental hygiene students' joint experiences, by number of participating students in each group making each comment

\begin{tabular}{|c|c|c|}
\hline Response & $\begin{array}{l}\text { Dental } \\
\mathrm{N}=375\end{array}$ & $\begin{array}{c}\text { Dental } \\
\text { Hygiene } \\
\mathrm{N}=117\end{array}$ \\
\hline
\end{tabular}

\section{Positive Responses}

Clinical setting

IPE in a clinical setting is beneficial.

IPE should be enforced in the clinical setting.

IPE helps with professional relationships.

IPE would help with teamwork in the professional setting.

Shadowing would help us.

There should be more referrals between dental and dental hygiene students.

Dental hygiene students should be a part of each dental student verticals.

We need more chairs for IPE in clinic.

Dentistry and dental hygiene complete each other.

Mission trip improves relationship between dental and dental hygiene students.

Subtotal

$\mathrm{N}=375$

$\mathrm{N}=117$

Classroom setting

I would like to have more IPE.

IPE in classes is a good idea.

IPE should be enforced in classroom settings.

We need projects to cause interaction between students.

Subtotal

$\begin{array}{cc}22 & 5 \\ 11 & 0 \\ 7 & 4 \\ 6 & 1 \\ 5 & 0 \\ 2 & 0 \\ 1 & 0 \\ 1 & 0 \\ 0 & 1 \\ 0 & 1 \\ 55(15 \%) & 12(10 \%)\end{array}$

General positive responses

Social/outside of class events would help with IPE.

IPE would help with communication.

IPE should be enforced to a certain point.

IPE is important.

We don't interact with students of the other program enough.

It is important to get to know/interact with students of the other program.

Interaction in school is nice.

IPE would help prevent dental student superiority.

Assigned seating influences interactions.

Not having IPE is holding back profession.

Subtotal

$\begin{array}{cc}21 & 6 \\ 15 & 4 \\ 7 & 3 \\ 4 & 0 \\ 47(13 \%) & 13(11 \%)\end{array}$

Role-related positive remarks

IPE would help with understanding roles.

I want to learn about the other program and its roles.

Subtotal

Total positive comments

$13(11 \%)$

Negative Responses

General remarks

IPE should not be enforced.

Too much IPE would hurt education.

Everything is fine the way it is.

Different schedules make IPE difficult.

Interaction between dental and dental hygiene students is difficult because they are

expected not to interact.

There is not enough time to implement IPE.

Our school does not facilitate respectful interprofessional relationships well.

Classrooms not big enough for IPE.

Dental hygiene students should realize that their work should be equal to the dental students' work ethic.

IPE is difficult because dentists and dental hygienists have different responsibilities.

IPE is a waste of time and money.

I feel like everything is about the dental students.

Dental hygiene students don't understand importance of dental students.

IPE is unnecessary for facilitating teamwork.

Dental and dental hygiene students will never be equal "partners."

IPE would add too much additional work.

$\begin{array}{lc}5 & 3 \\ 5 & 2 \\ 3 & 0 \\ 2 & 0 \\ 2 & 0 \\ 2 & 0 \\ 2 & 0 \\ 0 & 6 \\ 0 & 2 \\ 0 & 1 \\ 21(6 \%) & 14(12 \%)\end{array}$

$\begin{array}{cc}11 & 2 \\ 3 & 0 \\ 14(4 \%) & 2(2 \%) \\ 137(37 \%) & 41(35 \%)\end{array}$


Table 5. Open-ended responses concerning dental and dental hygiene students' joint experiences, by number of participating students in each group making each comment (continued)

\begin{tabular}{|c|c|c|}
\hline Response & $\begin{array}{l}\text { Dental } \\
N=375\end{array}$ & $\begin{array}{c}\text { Dental } \\
\text { Hygiene } \\
\mathrm{N}=117\end{array}$ \\
\hline IPE is difficult because dental students outnumber dental hygiene students. & 0 & 3 \\
\hline Teachers look down on dental hygiene students. & 0 & 1 \\
\hline IPE is difficult because dental students are older/have more life experience. & 0 & 1 \\
\hline IPE will not prevent dental student superiority. & 0 & 1 \\
\hline Subtotal & $31(8 \%)$ & $12(10 \%)$ \\
\hline \multicolumn{3}{|l|}{ Classroom setting } \\
\hline Our curricula are different from one another. & 7 & 1 \\
\hline Unequal work effort in group work/activities/projects. & 4 & 1 \\
\hline We do not have time for/should not do group project. & 4 & 0 \\
\hline Lab work does not overlap much. & 1 & 0 \\
\hline Subtotal & $16(4 \%)$ & $2(2 \%)$ \\
\hline \multicolumn{3}{|l|}{ Clinical setting } \\
\hline IPE will happen naturally in clinics (should not be enforced). & 1 & 0 \\
\hline Shadowing has no benefit for dental students. & 1 & 0 \\
\hline $\begin{array}{l}\text { Dental hygiene students don't help dental students in clinic because of our school's } \\
\text { policy. }\end{array}$ & 1 & 0 \\
\hline Subtotal & $3(1 \%)$ & 0 \\
\hline Total negative comments & $50(13 \%)$ & $14(12 \%)$ \\
\hline
\end{tabular}

Note: The survey used the terms "interprofessional," "interprofessional education," and "IPE" to refer to shared learning or practice between dentistry and dental hygiene.

dental hygiene students stated that education in joint classes was a good idea, and seven dental and three dental hygiene students noted they would like to see it enforced in classroom settings.

However, not all feedback was positive. Fifty dental students and 14 dental hygiene students gave negative responses concerning classroom-, preclinical/lab-, and clinic-based shared learning. The most common negative responses of the dental students were that shared education should not be enforced, that the curricula of the dental hygiene program and dental school were too different from each other to have it, and that too much shared learning would hurt dental education. The most common negative responses from dental hygiene students were that different schedules made having shared education difficult and that dental students outnumbered dental hygiene students when paired or grouped for projects and activities.

The final objective was to investigate whether the number of shared educational experiences was associated with more positive perceptions of benefits and increased numbers of curricular suggestions. While the number of joint classes correlated negatively with the "benefits of joint classes" index, there was no significant relationship to student-perceived benefits related to professional roles and suggestions concerning suggestions for classroom, preclinical/ lab, and clinical intraprofessional activities (Table 6). However, the students' year in their program was

Table 6. Correlation between indices and student characteristics and clinic experience for participating students

\begin{tabular}{|c|c|c|c|c|}
\hline Student Characteristic/Index & $\begin{array}{c}\text { Number of Joint } \\
\text { Classes }\end{array}$ & Year in Program & $\begin{array}{l}\text { \% Time in } \\
\text { Clinic Without } \\
\text { Interactions }\end{array}$ & $\begin{array}{l}\% \text { Time in Clinic } \\
\text { Collaborating on } \\
\text { Patient Care }\end{array}$ \\
\hline Year in program & -0.05 & 1 & $-0.14^{* *}$ & -0.01 \\
\hline$\%$ time in clinic without interactions & $0.20 * * *$ & $-0.14^{* *}$ & 1 & -0.08 \\
\hline$\%$ time in clinic collaborating on patient care & $0.19 * * *$ & -0.01 & -0.08 & 1 \\
\hline Benefits of joint classes index & $-0.15^{* * *}$ & 0.09 & -0.07 & 0.11 \\
\hline Professional role index & -0.03 & $0.15^{* * *}$ & -0.02 & 0.09 \\
\hline Classroom/lab-based interaction index & 0.02 & 0.03 & -0.09 & 0.09 \\
\hline Interactions in clinics index & -0.07 & $0.16^{* * *}$ & $-0.12^{*}$ & 0.09 \\
\hline
\end{tabular}

${ }^{*} \mathrm{p}<0.05 ;{ }^{* *} \mathrm{p}<0.01 ;{ }^{* * *} \mathrm{p}<0.001$ 
correlated with the "professional role" index: the more advanced the students were, the more they saw benefits in joint classroom activities for learning about each other's professional role, and the more they supported curricular suggestions for interactions in clinics.

\section{Discussion}

The importance of educating future dentists and dental hygienists in such a way that they embrace collaborative care has been recognized for more than two decades. ${ }^{1-4}$ However, the results of our study suggest that opportunities for shared educational experiences may not be optimally utilized on campuses that have both a dental school and a dental hygiene program. Gaining a better understanding of the perceptions of jointly educated dental and dental hygiene students concerning shared educational experiences, the benefits of these interactions, and suggestions for curricular changes could provide insights for academic deans and program directors who consider increasing shared experiences for these students in the future. We therefore collected data from 117 dental hygiene students in nine programs and from 375 dental students in six dental schools. While students from our home institution were overrepresented compared to students from other campuses, this sample allowed us to gather information that was not specific to one campus alone. In addition, including a qualitative component of coding openended responses should indicate this first research effort with dental and dental hygiene students on the same campus has an explorative component and can inspire future research.

There is an argument that joint educational efforts for dental and dental hygiene students should be called "interprofessional" instead of "intraprofessional," based on the claim that dentistry and dental hygiene are separate professions, rather than part of the same oral health profession, as defined by ADEA and used in previous articles on joint dental-dental hygiene education. ${ }^{8,12-15}$ Some may see a parallel with joint educational efforts in nursing and medicine, which are two professions, so those efforts constitute IPE. ${ }^{16-19}$ In 2017, Wilkins et al. defined five criteria of a profession: it requires specialized knowledge, methods, and skills; requires preparation from an institution of higher education; continuously enlarges its body of knowledge; functions autonomously in formulation of policy; and maintains high standards of achievement and conduct..$^{20}$ In addition, in 2017, Beemsterboer outlined criteria that must be met to become a profession and argued that dental hygiene fulfills them. ${ }^{21}$ Another consideration is that, in traditional dental practices, dental hygienists were always under the supervision of dentists and thus not considered professionals with autonomy. However, new developments such as direct access models imply that dental hygienists can initiate treatment based on their assessment of patients' needs without specific authorization of a dentist, treat patients without the presence of a dentist, and maintain a providerpatient relationship. ${ }^{22}$ The direct access model was introduced in the 1980s and is today endorsed by 42 states. ${ }^{23}$ Every state allows dental hygienists to provide some treatments without the supervision of a dentist, but administration of prophylaxis, sealants, and fluoride was included in the majority of the 42 states who use this model. ${ }^{22}$

This study utilized the distinct situation on 29 U.S. academic campuses with both a dental school and a dental hygiene program to explore which shared educational activities existed on these campuses, which benefits students perceived, and which suggestions for curricular changes they supported. The data showed that some institutions did not offer any shared classroom-based educational experiences. In addition, it is unclear how many of the student-reported joint courses would qualify as genuine intraprofessional experiences because no questions were included on the survey to explore whether these classes offered opportunities for dental and dental hygiene students to learn about, from, and with each other. ${ }^{4}$ The question concerning the status quo and future of intraprofessional education on these campuses, therefore, deserves further attention, especially in light of the parallel recommendations for optimal IPE implementation by Wilder et al. and Dow et al.,24 These authors argued that IPE should begin early in the education of health care professionals and continue throughout their entire curricula in both classroom and clinic settings and that IPE courses should include applicable content and competencies and contain discussions and interactions among the various health care professions students. Similarly, intraprofessional education should be intentional and formally taught in the classroom setting and reinforced in the clinical setting.

In addition to exploring the status quo of shared learning in these institutions, the second objective was to assess students' perceptions of benefits of intraprofessional education. Large percentages of the 
students agreed/strongly agreed that shared learning allowed students to learn what the other profession is all about, to gain a better understanding of each other's roles, and to develop better intraprofessional relationships. These findings concerning benefits are consistent with results from studies that found most students perceived shared learning was a good way to enhance pre-licensure professionals' attitudes towards each other, that a shared learning experience enhanced teamwork and collaboration, ${ }^{25-27}$ and that a deeper understanding of the professional roles and responsibilities of other dental professionals was gained. ${ }^{28}$ However, our data also showed a disconnect between these dental and dental hygiene students' responses concerning intraprofessional activities related to learning about each other's role, with the dental hygiene students' consistently responding more positively to these items than the dental students. This finding deserves further attention. If Dow et al. are correct that all members of the health care team must appreciate and respect the various roles, responsibilities, skills, and knowledge of its other members for the team to interact effectively, ${ }^{24}$ strong educational efforts are needed to ensure that all students realize this necessity.

This argument raises a question concerning which curricular suggestions could and should be implemented for improving intraprofessional education. The quantitative data analyzed in this study revealed two themes: first, a need and support for increased clinical interactions between dental and dental hygiene students, and second, support for more time for group work/discussions in classroom settings. These findings are consistent with recommendations that IPE should be emphasized in both classroom and clinic settings, with interprofessional care in clinics modeled by professors and then practiced by students. ${ }^{7}$ Additionally, Hendricson and Cohen argued that "group practice teams" should be implemented in clinical education as a way to promote working together in clinical teams. ${ }^{29}$

On the open-ended question on our survey about experiences with shared learning, the majority of comments from both the dental and dental hygiene students were positive. However, some made negative comments related to organizational issues such as scheduling joint time being difficult because of varying schedules and classrooms not being big enough. Other negative comments concerned an increase in the heavy course load that dental and dental hygiene students already have, stating that collaborative course work required too much additional work and that there was not enough time. These negative responses point to important barriers. However, they are consistent with previous findings. Already in 2001, Kassebaum et al. reported that the major concern about dental and dental hygiene curricula was that they included a large number of courses and clock hours that students must take to graduate. ${ }^{30}$ In 2006 , focus group interviews found that IPE was difficult because dental curricula were already overcrowded, and often there was lack of time for scheduling additional coursework. ${ }^{5}$ When asked about intraprofessional education, students reported a concern that it would be an "add-on" activity to an already packed curriculum. ${ }^{14}$ These concerns need to be considered carefully when developing shared activities and especially when introducing them to students.

One final question addressed in our study was whether having more joint classes would increase students' perceived benefits of shared learning. The findings did not support our expectation that more joint classes would correlate with more perceived benefits and more classroom and clinical interactions. However, it is striking that the more shared classes the students had, the more time they spent in clinic collaborating on patient care and the more aware they were that more time was spent in clinic without interactions. These findings deserve more in-depth research that carefully measures the quality of joint efforts.

This study had several limitations. First, students from only 12 of the 29 institutions with both a dental school and a dental hygiene program participated. It is unclear if the academic administrators did not forward the email to their students or if students did not take the time to respond. However, future research should explore ways to increase response rates. A second limitation was that the survey did not include questions about the specific collaborative interactions in the classroom and clinic in which students were involved. Future research could survey administrators in schools and programs to get more detailed information about intraprofessional didactic and clinical learning. For example, questions concerning the specific nature of shared educational experiences, such as whether the material presented and exams given were identical for the two groups of students, should be included in future surveys. Third, future surveys should also include questions concerning shared learning in community-based educational settings. In 2006, Rafter et al. reported that IPE and IPC occurred in community settings. ${ }^{5}$ Finally, asking faculty members who offer shared 
educational experiences in classroom, preclinical, and clinical settings which benefits and challenges they perceive and which curricular suggestions they would make could also be quite beneficial for the development of future intraprofessional experiences for these students.

\section{Conclusion}

In our study, not all programs utilized the opportunity to have a dental school and a dental hygiene program on the same campus to engage students in these programs in intraprofessional care. Radiology courses were most likely to be provided jointly for these students. About half of them agreed or strongly agreed that having joint classes allowed them to learn about what the other discipline is all about and to gain a better understanding of its roles. While the majority of both student groups agreed or agreed strongly that professional role discussions should occur in joint classes and that activities concerning professional roles should be integrated into joint classes, the dental hygiene students responded on average even more positively than the dental students. The dental hygiene students were on average also more positive concerning shared interactions in classroom and clinical settings. The more joint classes the students had, the more time they spent collaborating on patient care in clinics.

\section{Acknowledgments}

We want to thank the directors of the dental hygiene programs and the academic deans of the dental school programs for forwarding the recruitment email to their students and to thank the student respondents for taking time out of their busy schedules to respond to this survey. We also want to acknowledge Elizabeth Cahill's contributions to preparing the data for analysis.

\section{REFERENCES}

1. Field MJ, ed. Dental education at the crossroads: challenges and change. An Institute of Medicine Report. Washington, DC: National Academies Press, 1995.

2. Committee on Quality of Health Care in America. To err is human: building a safer health system. An Institute of Medicine Report. Washington, DC: National Academies Press, 2000.

3. Committee on Health Professions Education. Health professions education: a bridge to quality. An Institute of Medicine Report. Washington, DC: National Academies Press, 2003.
4. World Health Organization, Department of Human Resources for Health. Framework for action on interprofessional education and collaborative practice. Geneva: World Health Organization, 2010.

5. Rafter ME, Pesun IJ, Herren M, et al. A preliminary survey of interprofessional education. J Dent Educ 2006;70(4):417-27.

6. Oral health in America: a report of the surgeon general. Rockville, MD: U.S. Department of Health and Human Services, National Institute of Dental and Craniofacial Research, National Institutes of Health, 2000.

7. Wilder RS, O'Donnell JA, Barry JM, et al. Is dentistry at risk? A case for interprofessional education. J Dent Educ 2008;72(11):1231-7.

8. Formicola AJ, Andrieu SC, Buchanan JA, et al. Interprofessional education in U.S. and Canadian dental schools: an ADEA team study group report. J Dent Educ 2012;76(9):1250-68.

9. Furgeson D, Kinney JS, Gwozdek AE, et al. Interprofessional education in U.S. dental hygiene programs: a national survey. J Dent Educ 2015;79(11):1286-94.

10. Commission on Dental Accreditation. Accreditation standards for dental education programs. At: www.ada.org/ / media/CODA/Files/predoc.ashx. Accessed 15 Jan. 2018.

11. Commission on Dental Accreditation. Accreditation standards for dental hygiene education programs. At: www.ada. org/ /media/CODA/files/dh.ashx. Accessed 15 Jan. 2018.

12. American Dental Education Association. Intraprofessional education: where do we stand?At: www.adea.org/WorkArea/ DownloadAsset.aspx id=40054\&LangType $=1033$. Accessed 10 Dec. 2018.

13. Palatta A, Cook BJ, Anderson EL, Valachovic RW. 20 years beyond the crossroads: the path to interprofessional education at U.S. dental schools. J Dent Educ 2015;79(8):882-96.

14. Brame JL, Mitchell SH, Wilder RS, Sams LD. Dental and allied dental students' attitudes towards and perceptions of intraprofessional education. J Dent Educ 2015;79(6):616-25.

15. Jones VE, Karydis A, Hottel TL. Dental and dental hygiene intraprofessional education: a pilot program and assessment of students' and patients' satisfaction. J Dent Educ 2017;81(10):1203-12.

16. Engle J, Prentice D. The ethics of interprofessional collaboration. Nurs Ethics 2013;20(4):426-35.

17. Golom FD, Schreck JS. The journey to interprofessional collaborative practice: are we there yet? Pediatr Clin North Am 2108;65:1-12.

18. Bennett PN, Gum L, Lindeman I, et al. Faculty perceptions of interprofessional education. Nurse Educ Today 2011;31(6):571-6.

19. Reeves S, Zwarenstein M, Goldman J, et al. Interprofessional education: effects on professional practice and health care outcomes. Cochrane Database Syst Rev 2008;1(1).

20. Wilkins EM, Wyche CJ, Boyd LD. The professional dental hygienist. In: Wilkins EM, ed. Clinical practice of the dental hygienist. 12th ed. Philadelphia: Lippincott Williams and Wilkins, 2017:31-46.

21. Beemsterboer PL. Ethics and professionalism. In: Beemsterboer PL, ed. Ethics and law in dental hygiene. St. Louis: Elsevier, 2017:3-13. 
22. American Dental Hygienists' Association. Direct access to care. Updated April 2018. At: www.adha.org/resourcesdocs/7513_Direct_Access_to_Care_from_DH.pdf. Accessed 6 June 2018.

23. American Dental Hygienists' Association. Direct access 2018. Rev. April 2018. At: www.adha.org/resourcesdocs/7524 Current Direct_Access Map.pdf. Accessed 6 June 2018 .

24. Dow A, DiazGranados D, Mazamian P, Retchin S. Applying organizational science to health care: a framework for collaborative practice. Acad Med 2013;88(7):952-7.

25. Curran VR, Sharpe D, Flynn K, Button P. A longitudinal study of the effect of an interprofessional education curriculum on student satisfaction and attitudes towards interprofessional teamwork and education. J Interprof Care 2010;24(1):41-52.

26. Fried JL. Confronting human papilloma virus/oropharyngeal cancer: a model for interprofessional collaboration. J Evid Base Dent Pract 2014;14(Suppl 1):136-46.
27. Morison S, Marley J, Stevenson M, Milner S. Preparing for the dental team: investigating the views of dental and dental care professional students. Eur J Dent Educ 2008;12(1):23-8.

28. Salazar FBC, Andiappan M, Radford DR, Gallagher JE. Attitudes of the first cohort of student groups trained together at the University of Portsmouth Dental Academy towards dental interprofessional education. Eur J Dent Educ 2012;21(2):91-100.

29. Hendricson WD, Cohen PA. Oral health in the 21st century: implications for dental and medical education. Acad Med 2001;76(12):1181-207.

30. Kassebaum DK, Hendricson WD, Taft T, Haden NK. The dental curriculum at North American dental institutions in 2002-03: a survey of current structure, recent innovations, and planned changes. J Dent Educ 2004;68(9):914-31. 